\title{
A Call to Action \& Open Invitation
}

\section{Cody Miller Pyke, JD, LLM, MSBe}

The National Perinatal Association (NPA)is an interdisciplinary organization that strives to be a leading voice for perinatal care in the United States. Our diverse membership is comprised of healthcare providers, parents \& caregivers, educators, and service providers, all driven by their desire to give voice to and support babies and families at risk across the country.

Members of the NPA write a regular peer-reviewed column in Neonatology Today.

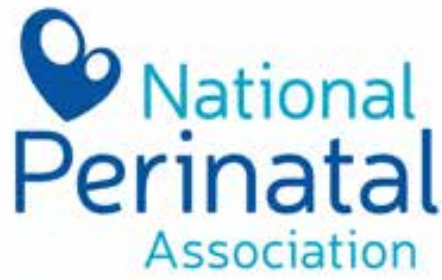

Educate. Advocate. Integrate.

"In an oversimplified way, equality in health care can be understood as applying the same standard of care to all patients regardlless of their demographics. However, true health equity seeks to improve the health of disproportionately affected minority groups to the same level as the majority."
"Equity" and "Justice" are not ordinarily the first two words that come to mind when one thinks about the practice of perinatology. However, during the global SARS-CoV-2 (COVID-19) pandemic-wherein African Americans, Native Americans, and LatinX people face disproportionately greater mortality, morbidity, and financial harm than Whites (1) - these two words are at the forefront of public consciousness in the United States. "Equity" should not be misunderstood as "equality." The latter term speaks to providing equal (i.e., "identical") support to diverse individuals, regardless of their different levels of need. The former instead seeks to provide whatever amount of support is necessary to each community in order for all communities to have their needs met. In an oversimplified way, equality in health care can be understood as applying the same standard of care to all patients regardless of their demographics. However, true health equity seeks to improve the health of disproportionately affected minority groups to the same level as the majority.

\section{"Early studies of the impacts of the COVID-19 pandemic on maternal and infant health have revealed troubling realities."}

Issues of equity and justice in maternal and infant health are not novel, (2) and, in fact, go back to (and arguably persist from) the practice of chattel slavery in the United States. (3) Early studies of the impacts of the COVID-19 pandemic on maternal and infant health have revealed troubling realities. A scoping review published in Reproductive Health of 97 peer-reviewed publications on the pandemic's effects on perinatal health found, inter alia, evidence of significantly reduced access to antenatal and postnatal health services, increased mental health illness among pregnant people and new gestational parents who recently delivered, widely variable and inconsistent guidance on pregnancy and breastfeeding during the pandemic, increased incidence of C-sections likely attributable to more aggressive management of pregnancy, increased domestic violence, and disproportionate rates of loss of employment. (4)

The COVID-19 pandemic has undoubtedly put maternal and infant health under a critical lens. So when I had the privilege of being named one of the co-chairs for the $\mathrm{Na}$ tional Perinatal Association (NPA) annual conference for 2021-along with my colleague, Dr. Tiffany Willis-we knew immediately what the theme of this conference must be: Perinatal Care at the Intersection of Health Equity and Social Justice. NPA believes that everyone has the right to high-quality, respectful perinatal care. We also acknowledge the unfortunate reality that in the United States, the health care community has failed to deliver equitable care to people of diverse socioeconomic backgrounds. As an organization, our core goals are to educate professionals and communities, advocate for patients and families, and integrate best practices across perinatal care by fostering interdisciplinary collaboration. In accordance with these core goals, NPA's 2021 conference will bring together a diverse body of speakers to educate, advocate, and integrate on behalf of the diverse bodies and communities we serve as perinatal health professionals. The 2021 Conference will be held over three days, from December 1 to December 3, 2021, in Aurora, Colorado, U.S.A. The conference will be a time to critically examine and discuss not only the nuances of clinical care for pregnant patients and neonates but also our own biases and the health infrastructures that lead to disparate outcomes. It will be a time to commit (or, for many, recommit) to a call to action-that perinatology as a field ensures every pregnancy, every baby, and every parent receives trauma-informed, family-centered, and equitable care.

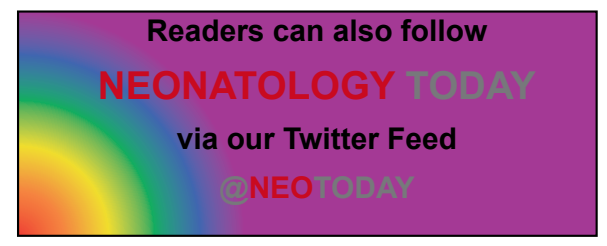


Amidst the pandemic, it can be tempting to maintain the status quo to avoid adding additional strains to an already stressful and uncertain time. However, while COVID-19 is new, the issues of inequity and injustice in maternal and infant health are not. We cannot afford to wait for the pandemic to subside or, worse, wait for another pandemic to motivate us into action. Therefore, Dr. Willis and I invite you to attend the National Perinatal Association's 2021 Annual Conference. Both in-person and remote options are available at this time, and we are closely monitoring Centers for Disease Control and local health authority guidelines regarding best practices to ensure safety for attendees and presenters. We encourage academic poster submissions by professionals, trainees, and students alike and look forward to seeing you-even if on a computer screen-very soon.

"Therefore, Dr. Willis and I invite

you to attend the National Perinatal

Association's 2021 Annual Conference.

Both in-person and remote options are

available at this time, and we are closely

monitoring Centers for Disease Control

and local health authority guidelines

regarding best practices to ensure safety for attendees and presenters."

Respectfully,

Cody Miller Pyke, JD, LLM, MSBe

MS4 - Baylor College of Medicine

\section{References:}

1. Tai, D. et al. (2021). The Disproportionate Impact of COVID-19 on Racial and Ethnic Minorities in the United States. Clin Infectious Diseases, 72(4), 703-706. https://doi. org/10.1093/cid/ciaa815

2. Taylor, J. et al. (2019). Eliminating Racial Disparities in Maternal and Infant Mortality: A Comprehensive Policy Blueprint. Center for American Progress. Online. URL: https://www.americanprogress.org/issues/women/reports/2019/05/02/469186/eliminating-racial-disparitiesmaternal-infant-mortality/; see also, Miller, C. C., \& Tuan, E. (2018). BLACK + PREGNANT = DEATH? Racial disparities in perinatal morbidity and mortality in the United States. Neonatology Today, 13(11), 28-29.

3. Owens, D. C., \& Fett, S. M. (2019). Black Maternal and Infant Health: Historical Legacies of Slavery. Am J Public Health, 109(10), 1342-1345. https://doi.org/10.2105/ AJPH.2019.305243

4. Kotlar, B. et al. (2021). The impact of the COVID-19 pandemic on maternal and perinatal health: a scoping review. Reprod Health, 18(10). https://doi.org/10.1186/s12978-021-

\section{$01070-6$}

Disclosure: The National Perinatal Association www.nationalperinatal.org is a 501c3 organization that provides education and advocacy around issues affecting the health of mothers, babies, and families.

NT
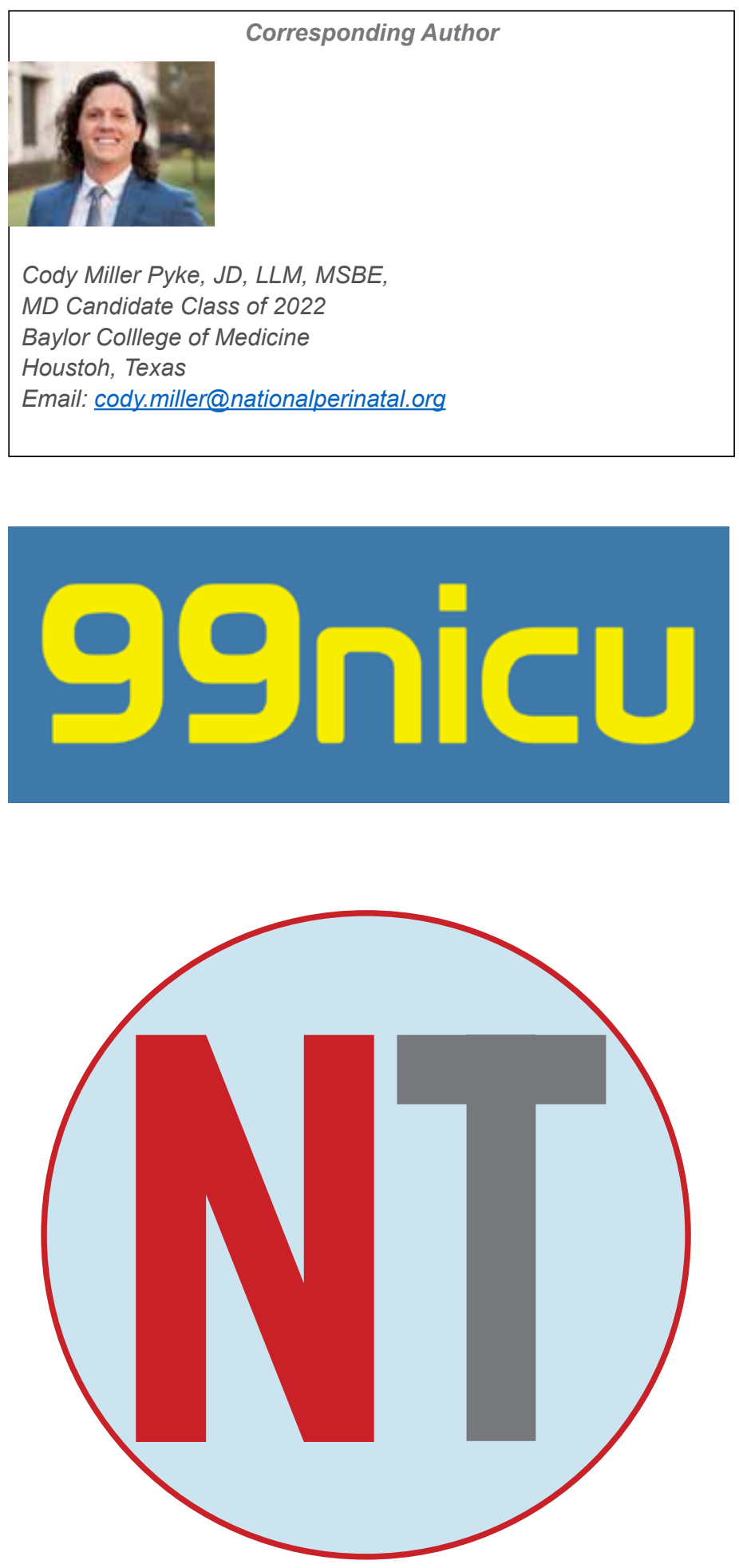